\title{
NEW PREMIUM CARS SALES PROMOTION BASED ON THE SYSTEM OF PRE-OWNED CARS SALES TO LOYAL CUSTOMERS
}

\author{
Mark Evgenyevich Koryagin* \\ Kemerovo State Agricultural Institute, Russia
}

The decline in sales of new cars in Russia leads to the necessity for a more complicated procedure connected with the sale of pre-owned cars. Creating a sequence of premium brand pre-owned cars purchasing and selling will lead to an increase in new car sales and increase customers' loyalty. A mathematical model of the formation of car purchase and transaction chains is proposed. The developed program module allows to create the required number of transaction chains based on customers ' requirements. A numerical example demonstrating the effectiveness of the module for the regional car dealerships is provided.

Key words: Car dealer, Premium brand, Decision tree, Sales promotion

\section{INTRODUCTION}

The car market in Russia is currently experiencing weak sales and little growth. The low level of motorization and a significant increase in the level of household incomes brought the Russian car market to the first place in Europe in the 2000's. However, the car market appeared sensitive to the crisis developments in the economy, which led to a significant reduction of car sales in Russia in recent years. In the period of recession, a decrease in consumer income forces dealers to sell cars below their invoice price and dealers have to compensate for their losses by selling spare parts and the servicing of cars [02].

One of the ways to support the car market in Russia is to turn to the state government programs that promote the replacement of old vehicles with modern ones. However, they do not apply to all segments of the auto market. For example, the Russian Government provides subsidies to encourage car owners to trade-in their old cars to buy new ones. The program is focused on domestically produced cars with subsidies applying to cars whose price does not exceed the set value (which increased from 9,000 euros in 2009 to 16,000 euros in 2016). In Europe market demand for cars is effectively managed by stimulating the replacement of older cars with more economical and eco-friendly vehicles [13].

Nowadays, manufacturers pay increasing attention to the market of pre-owned cars. Initially, this segment of the car market was supposed to create near-direct competition with new cars. But the strategy is changing now and manufacturers are trying to increase car residual value to raise customer loyalty to their brand [06]. On the other hand, car durability is an bottleneck in new car sale, so car durability factor should be taken into account in the manufacture of new cars [07]. Therefore, it is worth thinking about the fate of a new car when selling it to the buyer.

A considerable amount of literature has been published on relationships between buyers, sellers (especially dealerships) and manufacturers. As for the interaction between buyers and dealers, it has dramatically changed in recent years and this change can be accounted for by the car market globalization [01]. So the car market is influenced by the Internet, which provides information about car prices and quality of cars, a dealer's honesty, in which case dealers have little opportunity to overprice. For example, in Denmark price differences for cars in various regions could reach $15 \%$ a few years ago though nowadays there is no disparity in pricing [08].

Knowledge about special offers of different dealers and customers' patience allows to reduce costs by an average of $0.5-2 \%$ when buying a car [10]. Most dealers pay a lot of attention to discounts on cars, while the factors of personal relationships and service packages are not sufficiently used to promote the sales [12]. In the Internet era dealers must build a novel type of relation with customers, because customers can easily get information about car pricing online. 
And negotiations between a dealer and a customer become an important part of a car sale procedure.

Customers could be classified into three categories in relation to the dealer: 1) the customer focused on friendly relations; 2 ) the customer focused on getting service packages; and 3) the disloyal customer.

Some dealers don't take into account the customer loyalty factor as they wish to get unreasonably high income, which leads to customers' breaking any relations with the dealer [04]. Termination of the relationship is a wake-up call for the dealer. Researchers identify determinants of relationship termination, such as changed needs, service failures, or variety seeking [11]. However, not all customers are ready to cut off all contact with the dealer, some are ready for relationship recovery.

Customer loyalty to the brand is very important for manufacturers. Vigripat and Peng showed the effect of service quality, brand image and trust building as well as a positive recommendation of the model and brand on a desire to buy the same car [15]. Moreover, it was found that brand image was not an important factor for repurchasing a car. On the other hand, it is essential for the brand to implement the customer expectations during the re-purchase, i.e. the customer should have confidence in the brand.

The article [14] showed that only large dealers could retain customers of the brand, customers' loyalty to the premium brand was higher than to the economy class cars.

The behaviour of the premium brand customer depends on many factors. In particular, cultural differences lead to a different perception of the value of a premium car [03]. Making a decision about the premium brand car purchase is associated not only with economic or rational factors, but also with the customer psychology, the culture of the country. Eastern collectivism increases Mercedes sales, and western individualism increases BMW sales.

This article discusses the model for BMW brand sales promotion in Russia. There are many brands in the world while everybody is certain to know about the BMW brand. Having this brand car is a symbol of success, dynamic and reputable life [09]. The main advantage of the BMW brand has been its style commitment for over half a century.
BMW customers tend to be more loyal to the brand; therefore, it is necessary to create tools to help customers exchange cars. The sales management model should consider the durability of the cars together with a large number of customers who want to buy a used car of a premium brand. The model presented in this article allows to improve the quality of customer service and increase car sales as well as improve customerdealer relationships.

\section{MODELLING CAR SALES}

In car sales, it is possible to identify three types of participants, i.e. decision makers: customers, dealers, and manufacturers [02]. Customer behaviour is described primarily by using the logit functions $[02,05,13]$. The main sources of getting information are the car dealership surveys $[03,16]$. In the article [04] it is proposed to identify the customer behaviour using computer testing. A more sophisticated model is associated with household behaviour, because. if the family has more than one car then family members expose different requirements to the dealer [01].

The behaviour of the dealer is associated with determining the price and terms of payment, negotiations, additional options, etc. The manufacturer sets sale strategies either together with a dealer or independently. Albuquerque showed that the manufacturer determines the number of dealerships depending on the market conditions [02].

Thus, the participants' goals and strategies of the car market determines the necessity for reaching a compromise or balance [01, 02, 05, 07]. Different results can be explained by the difference in the number of participants, their goals and their model of behaviour.

In this article, the model of the manufacturer behaviour is not considered. The change in the dealer's strategy, which is caused by the decrease in sales, is associated with increased sales of preowned cars, which allows to stimulate new cars sales under the scheme "trade-in".

The relationship between a customer and a dealer in car purchasing process is described as the selection of proposals and negotiations about the sales price in transaction chain at the top of which is a new car.

Car sales in Russia have been decreasing since 2014 though the decrease in premium brand cars sales has not been so drastic. In this article, we are considering the BMW sales performance 
in Russia and in Krasnoyarsk region. Figure 1 shows that in 2014 dealers managed to increase the sales despite the overall Russian tendency towards decline.

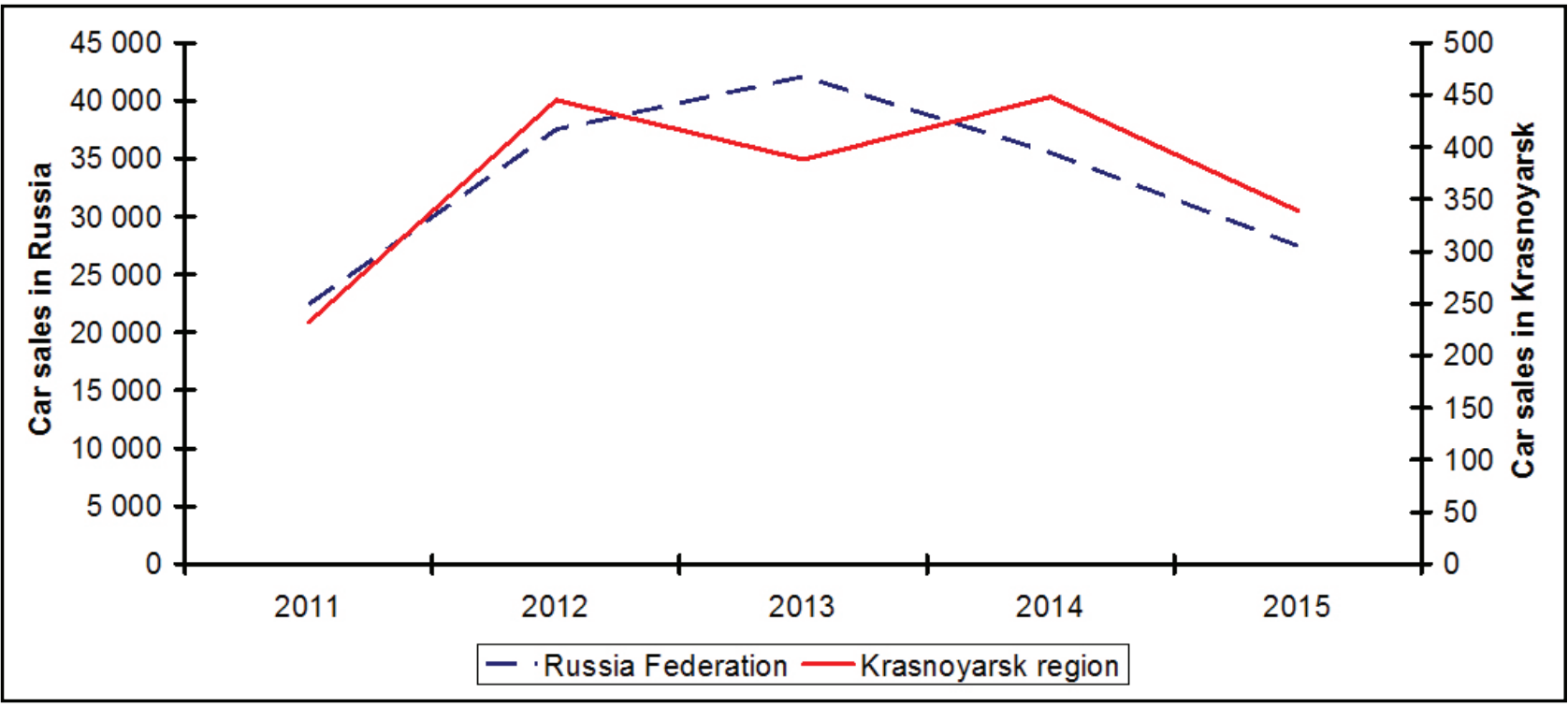

Figure 1: Regional BMW sales

A solution to improve the situation (to promote the demand) could be the increase in the preowned cars sales. Our research is focused on BMW 5 Series cars. The chart below shows the ratio of new-to-used cars sold by the dealership. What is interesting in these data is that the num- ber of sold pre-owned cars is growing rapidly and recently it has increased threefold. In 2013 for 1 sold pre-owned car there were 17 new cars sold; in 2015 there were only 6 . In addition, the proportion of BMW cars increased from 50 (3\% to $6 \%)$ to $70(11 \%$ to $17 \%)$.

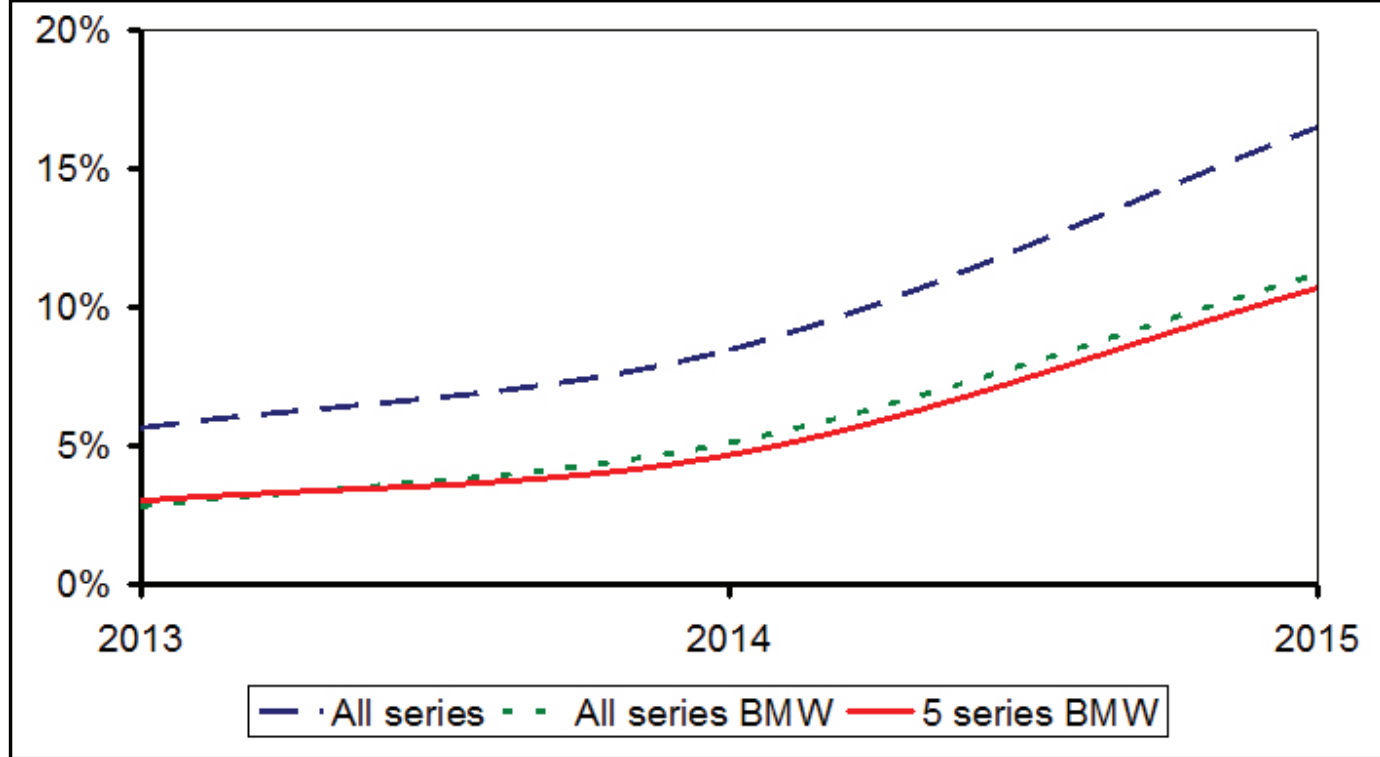

Figure 2: Ratio of sold pre-owned and new cars

Thus, the number of loyal-to-the-brand customers is increasing. It is necessary to take this advantage to increase the sales of new cars. The model of the BMW 5 series cars sales is offered in the article. It should be noted that the BMW sales are around $15 \%$ of the sales volume in Krasnoyarsk region. 


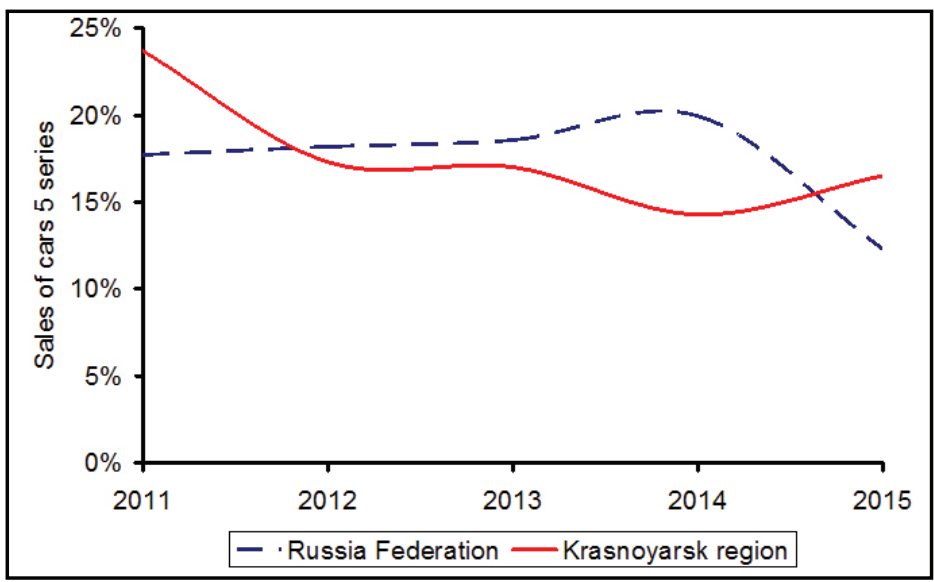

Figure 3: BMW 5 Series sales trends, volume of new cars

\section{PROBLEM DESCRIPTION}

We will show how the proposed multilevel system works with the data taken from the database of "ElitAvto" (BMW 5 Series cars). The system consists of several levels. A certain model of the BMW 5 Series cars is assigned to each level. During the period from 1977 to 2014, six models of the BMW 5 Series cars were produced by BMW Group. Earlier models of BMW cars (produced in the 1970s - 1980's) are not considered as their number is very low and there is little demand for them. Therefore, our system consists of five levels and depends on the number of models that have a certain demand and liquidity position.

The first level (highest level) includes new BMW 5 Series cars in stock, all the cars are situated in the showroom. This model has been produced since 2010. The bodies of these cars are labelled F10. The cost varies from 30,000 to 40,000 euros. The first level is highlighted apart from the others, since these cars are new, and the sale of these cars is the dealer's priority. All the levels that follow include pre-owned cars. The second level includes the cars of the same model as those of the first level but the second-level cars have a mileage. The cost of these new cars is significantly lower and it varies from 14,000 to 30,000 euros. The car owners whose cars could belong to the second level are more likely to become potential candidates for the purchase of a new car. On the third level there are cars produced between 2003 and 2009. The bodies of these cars are labelled E60. The costs fluctuate from 10,000 to 17,000 euros. The third-level car owners may be both second-level and firstlevel customers. On the fourth level there are car produced between 1995 and 2003. The bodies of these cars are labelled E39. The cost is from 4,000 to 10,000 euro.

Finally, the fifth level includes cars of the same 5 Series produced between 1988 and 1995. The bodies of these cars are labelled E34. The cost is from 3,000 to 4,000 euros.

The diagram below shows how car owners move through the levels. Currently, there are 348 potential customers who could buy a new BMW 5 Series car (F10) in the customer database of the dealership "ElitAvto". The potential customers are registered in the dealership system CRM, GoldMine program. According to the data in the program, 52 of the 348 potential customers are already BMW car owners. It is necessary to encourage BMW car owners and potential customers to purchase new cars, which will lead to the growth in sales of premium cars. It will increase the dealer's profitability and stability in the market. It requires developing a mathematical model of making pre-owned car transaction chains based on the data collected from GoldMine.

\section{MATHEMATICAL MODEL OF SALES MANAGEMENT}

There are $\mathrm{N}$ requests in the database. For each request the level of a customer car $a_{i}$ is identified as follows: 0 - no car, 1 - a new car with body F10, 2 - a used car with body F10, etc. The wanted vehicle is in request $b_{i}$. The customer is ready to pay d_i for the replacement. At the same time the market prices of level (body) $\mathrm{j}$ car is $C_{i}$. It means that the additional payment for the request shall be $C_{b i}-C_{a i}$. Thus, a customer's "intransigence" could be defined as the difference between the market additional payment and the price that the customer is ready to pay.

$e_{i}=C_{b i}-C_{a i}-d_{i}$

Journal of Applied Engineering Science 15(2017)1, 407 


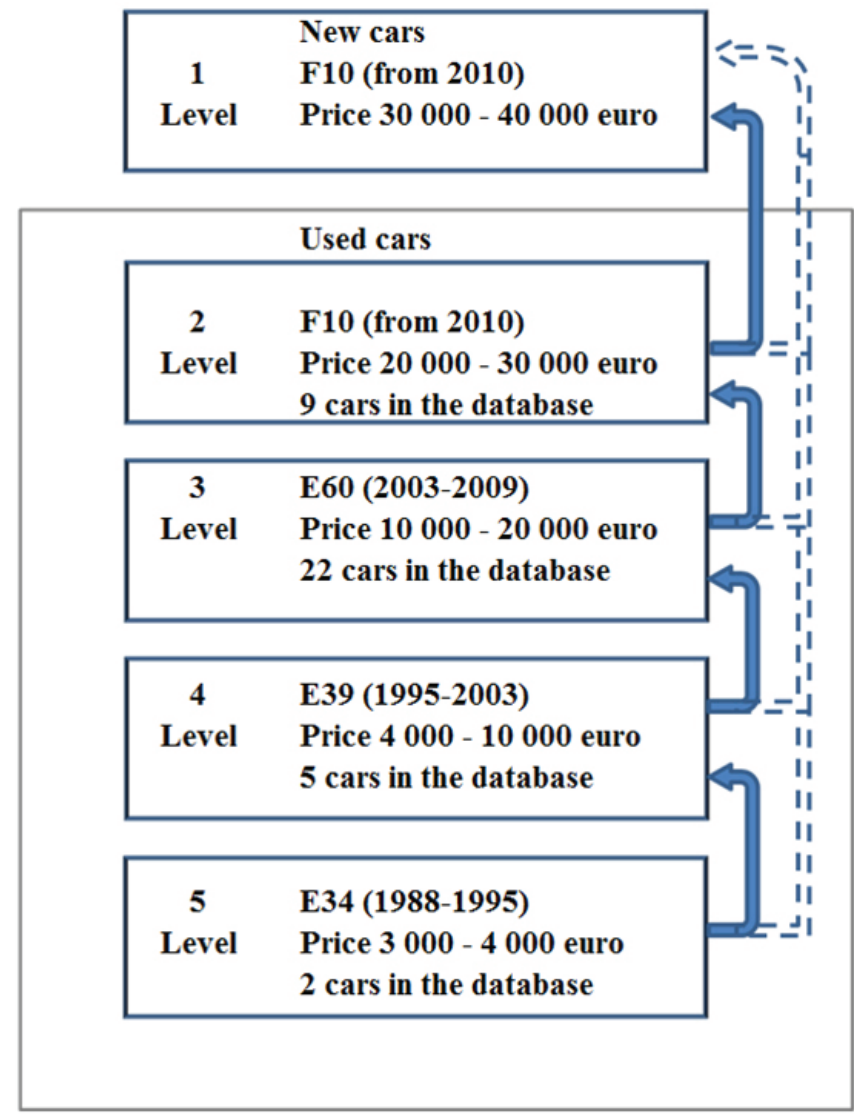

Figure 4: BMW 5 Series replacement and sales

The transaction chain is calculated from the requests with numbers $i_{1}, i_{2}, i_{3}, i_{4}, i_{5}$ (the first index shows that a customer with no car wants to purchase an old car). However, some numbers may be empty (a customer wants to purchase a car more than a level higher).

This chain will have the following intransigence level (the divergence from market price).

$e_{i 1}+e_{i 2}+e_{i 3}+e_{i 4}+e_{i 5}$

At the same time, the importer could offer a discount $\Delta \mathrm{C}$.

The remaining sum $\Delta C-e_{i 1}-e_{i 2}-e_{i 3}-e_{i 4}-e_{i 5}$ is expected to be divided between the participants in equal shares or in proportion to the cost. It is also possible for the dealer to receive the difference.

If the condition is not fulfilled, the dealer should help the customers to come to agreement. It is offered not to change the price for customers who objectively value their car $\left(e_{i}<0\right)$ (their request will be fulfilled). For uncompromising customers it is necessary to increase the additional payment (in comparison with the desired price) proportionally to the cost or in equal parts. The problem of finding a chain is not very difficult and can be solved by enumeration. The algorithm starts with the final customer (who is going to buy a new car). The customer has a car to sell. There are customers for this car. If this customer has no car, the chain ends, and the search for customers continues.

The number of possible chains depends on the number of requests. For example, if all customers want to replace their cars a level higher, the total number of chains will be:

$$
\prod_{i=1}^{5}=1^{n i} \text {, }
$$

where $n_{i}$ - a number of $i$ - level customers.

If a customer wants to purchase a car several levels higher, the number of chains will be lower. For example, if there are 10 requests on each level, the number of chains is not more than 100000 . And if there are 100 requests on each level, the number of chains will not exceed $10,000,000,000$.

Supposing $A_{j}$ is a chain that includes custome $r s\left\{a_{j 1}, a_{j 2}, a_{j 3}, a_{j 4}, a_{j 5}\right\}$, then the set of all chains is $A$. The variable is a disjoint set of chains $X A$ (each pair of chains $X_{i}$ A and $X_{i} \quad A$ meets the condition $\mathrm{X}_{\mathrm{i}} \cap \mathrm{X}_{\mathrm{i}}=$ ) .

Obviously, the chains include part of the customers and, at the same time, all the chains cannot be implemented. It is needed to find a set of disjoint chains X. So it is important for the dealer to find a set of chains with the highest number of them, which will allow realizing the maximum number of new cars:

$|\mathrm{X}| \rightarrow$ max.

The solution of the problem (searching a set of chains) also depends on the number of chains. Apparently, the number of variants does not grow as fast as the number of chains that depend on the number of requests. Still, when the number of chains is more than several thousands, it is difficult to solve the problem with a modern computer (time spent can amount to days).

\section{SOLUTION ALGORITHM}

A more challenging task is to calculate a set of transaction chains. In this case, we need to assign non-greedy customers to different chains in order to increase the number of chains. Various chains are made for this purpose. Among these variznts the chains with the leval of greed clower than a price-cutting level gre selected; otherwise, it will be difficult to persuade customers to increase the additional payment. Next, with the help of the exhaustive search algorithm (also based on the decision tree) a set of chains with disjoint requests is 
selected (i.e. the request cannot be in more than one chain). A set of chains with the highest number of chains is selected, which is the optimal solution. After that, the negotiations on each chain are conducted. The reduction in the number of possible chains will help to solve the problem of finding a set of chains by the exhaustive search effectively. A small dealership (regional level) does not need to make hundreds of chains. It is enough to make several disjoint chains for the current work. For example, up to 30 transactions of sale and purchase are necessary to be completed for 5 chains. In addition, negotiations with customers on the price of the car are essential to be conducted. So the amount of work for the regional dealer will be big enough for a small number of chains. Therefore, the exhaustive search algorithm can be used to solve the problem. Also, it should be mentioned that requests for cars constantly come and after the proposed chains are implemented, a new set of chains on the updated customers ' requests can be created. As mentioned above, every chain can be estimated by the degree of greed. Naturally, a chain where greed is high is more difficult to implement. Therefore, it is proposed to limit the greed of chains. In other words, we identify the maximum possible chain divergence from the current price of a new car. Chains with a large divergence are not considered since it will be difficult to persuade customers to significantly increase the price. If we divide customers into greedy and disinterested ones, chains of more disinterested customers are formed if a divergence is small. Therefore, the same disinterested customers will be in different chains and a number of disjoint chains will be low. If the maximum divergence from a new car price is increased, new chains will be formed in which disinterested customers will be distributed to different chains, i.e. the greed of some customers will be compensated by the disinterestedness of others. At start of the program information about car prices (table "Body price") and customer requests (table "Customers" offers") is uploaded from text files. It is necessary to set "The maximum bargaining percentage" of a new car price. Bargaining is aimed at importer and dealer discount and the opportunity to persuade the customer to increase the additional payment. The solution consists of two steps. After pressing the button "Chains", the table "All chains", satisfying the restriction on "Maximum bargaining", is calculated. The button "Solution" allows to find the maximum number of disjoint chains from the table with all chains. The solution is written in the table "Solution". The table below shows the chain (number of customer requests) and the price of a new car that customers are ready to buy the car for.

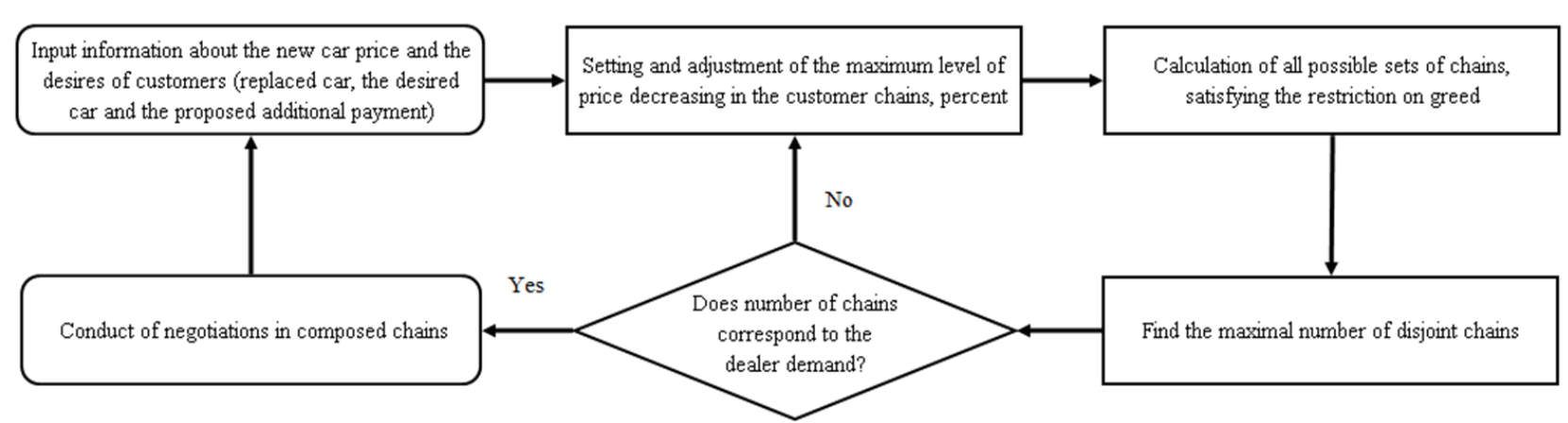

Figure 5: The algorithm block scheme

\section{NUMERICAL EXAMPLE}

The sorted data were added to the sales management program. When the program is launched, the data on the car prices (table "Body price") and customer requests (table "Customers" offers") are uploaded from the text files. Then, "The maximum bargaining percentage" (price for new cars) is set up. Bargaining is aimed at importer and dealer discount and also the dealer' opportunity to persuade the customer to increase the additional payment. The solution consists of two steps. After pressing the button "Chains", the ta- ble "All chains" satisfying the restriction of "maximum bargaining" is calculated. The button "Solution" allows to calculate the maximum number of disjoint chains from the table of all chains. The solution is written in the table "Solution". Figure 7 shows the amount of chains (number of customer requests) and the maximal number of disjoint chains. The number of possible chains depends on the discount. The larger the discount, the greater the number of chains. The algorithm is suitable for many other cars (different makes and brands). In this case, a more detailed questionnaire for the customer should be developed. 


\begin{tabular}{|c|c|c|c|c|c|c|c|c|c|c|c|}
\hline$O$ chais & Is creatior & & & & & & & & & -1[ & $x$ \\
\hline Price & & & & ustome & rs' offers & & & & I chains & & \\
\hline Body & Price & & $\mathrm{N}$ & Exist Bods, & Desired Body & Price & 唋 & $\mathrm{N}$ & Chain & Price & 㒳 \\
\hline E34 & 3900 & & 1 & E34 & E39 & 3800 & 是 & 0 & 40142137 & 35000 & 显 \\
\hline E39 & 7900 & & 2 & E34 & E60 & 4300 & & 1 & 40142237 & 35000 & \\
\hline E60 & 13900 & & 3 & E39 & E60 & 5400 & & 2 & 40152137 & 35000 & \\
\hline F10 & 23300 & & 4 & E39 & E60 & 6300 & & 3 & 40152237 & 34700 & \\
\hline F10 New & 39000 & & 5 & E39 & E60 & 6400 & & 4 & 41142136 & 35100 & \\
\hline Maxima & al pricecu & nq $7 \div$ & 6 & E39 & F10 & $10 \quad 000$ & & 5 & 41142137 & 34800 & \\
\hline & & & 7 & E39 & F10 New & 24000 & & 6 & 41142236 & 35300 & \\
\hline Disjoin & t chains: & & 8 & E60 & F10 & 9800 & & 7 & 41142237 & 34900 & \\
\hline $\mathrm{N}$ & Chain & Price & 9 & E60 & F10 & 10500 & & 8 & 41152136 & 35000 & \\
\hline 4 & 41142136 & $\begin{array}{ll}35 & 100\end{array}$ & 10 & E60 & F10 & 11000 & & 9 & 41152137 & 34500 & \\
\hline 33 & 4852237 & $\begin{array}{ll}35 & 200\end{array}$ & 11 & E60 & F10 & 11500 & & 10 & 41152236 & 35200 & \\
\hline & & & 12 & E60 & F10 & 11500 & & 11 & 41152237 & 34900 & \\
\hline & & & 13 & E60 & F10 & 12000 & & 12 & 42142037 & 34600 & \\
\hline & & & 14 & E60 & F10 & 12000 & & 13 & 42142134 & 34600 & \\
\hline & & & $\overline{15}$ & tafn & F1n & 12 $5 \mathrm{n}$ & v & 14 & | 12143135 & $2 A$ anก & 国 \\
\hline & & 1. Find $\mathrm{a}$ & & hains & 2. Fin & d maxi & imal & & $t$ of chains & & \\
\hline
\end{tabular}

Figure 6: Program screenshot

There are limitations of the use of the algorithm in practice. The increasing number of cars leads to a growing number of opportunities for buying and selling vehicles. For example, the number of customers on each level is $\mathrm{N}$ and each customer wants to buy a car only a level higher. Thus, the number of possible combinations will be $\mathrm{N}^{\wedge} 5$ (for 5 levels). The number of variants (set of disjoint chains) will be $(\mathrm{N} !)^{\wedge} 5$. This estimate shows the maximum number of variants, but in reality, the number is lower. For example if we have to find only two transaction chains, the number of variants is $\left(N^{\wedge} 2-N\right)^{\wedge} 5$. Therefore, we cannot use the algorithm for thousands of customers. There are a lot of advertisements for cars on the Internet and the algorithm cannot be used to calculate the number of all possible transaction chains in this case. The algorithm is designed primarily for dealerships' databases.

\section{CONCLUSION}

A special feature of premium brands is their higher customer loyalty. Car brand loyalty can lead to customers returning to the same dealership when it is time for them to trade in their cars. And dealership owners are greatly interested in their customers' exchanging their cars. Therefore, a mathematical model for selling cars of one brand (BMW) is proposed in the article. The model takes into account a customer's desire to replace his/her car, and a dealer should help the customer to sell his/her old car. The necessity of solving the problem has arisen in view of the growth of customer interest to buy cars under the trade-in scheme in Russia in the last few years. The model allows to find a transaction chain for the promotion of new cars.

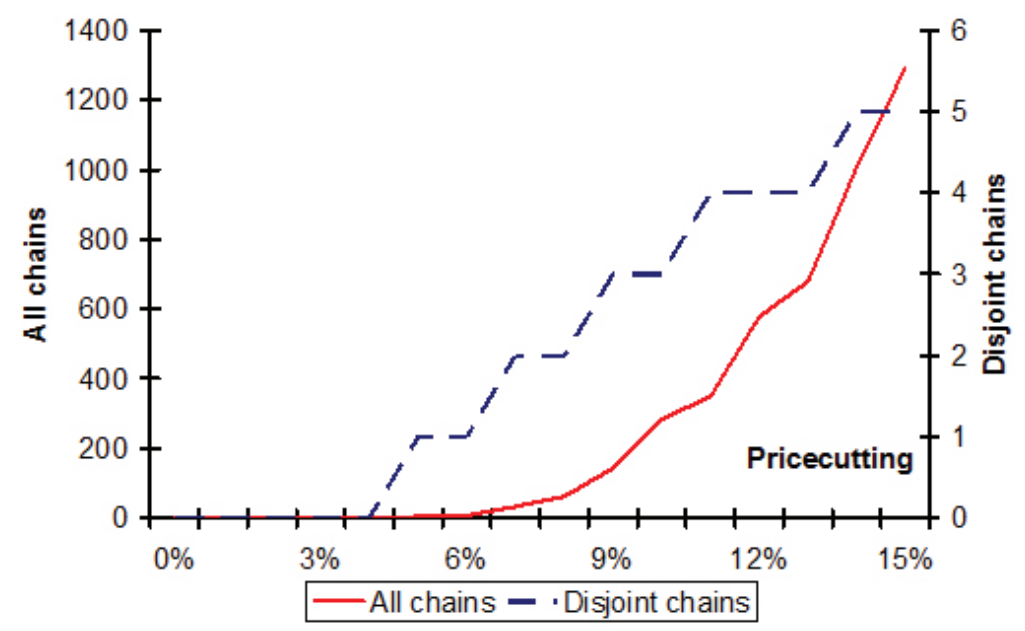

Figure 7: The number of chains, the dependence on discount 
The solution of the problem consists of two stages: the formation of all the possible chains and finding the set of disjoint chains. The exhaustive algorithm can be used for a small number of sold cars, but heuristic algorithm is required for dealers with big customer databases. Development of heuristic algorithms to solve the problem for a larger number of cars of different brands is the next stage of the research. Dealers can use the model to create conditions for negotiations with buyers. But transactions depend on the ability of dealers and customers to make mutual concessions. After the introduction of the proposed customer loyalty management techniques companies' profitability and competitiveness are supposed to increase. The ability to realize the existing car at a fair price is the most significant factor, which has an impact on the purchasing decision. New cars sales plan fulfilment is the multilevel potential customers management model. A system CRM with the use of the multilevel customer management model can be integrated with GoldMine or similar software.

\section{REFERENCES}

1) Abraham, R., Zikiye, M.W., \& Harrington, C. (2015). A Theoretical Model of Competitive Equilibria in the New Car Market. Theoretical Economics Letters, 5, 196-211. doi:10.4236/tel.2015.52024

2) Albuquerque, P., \& Bronnenberg, B.J. (2012). Measuring the Impact of Negative Demand Shocks on Car Dealer Networks. Marketing Science, 31(1), 4-23. doi:10.1287/ mksc. 1110.0659

3) Anurit, J. (2002). An investigation into consumer behaviour towards the purchase of new luxury cars in two culturally distinct countries: The UK and Thailand. Middlesex University. PhD diss.

4) Buskens, V., \& Weesie, J. (2000). An Experiment on the Effects of Embeddedness in Trust Situations: Buying a Used Car. Rationality and Society, 12(2), 227-253. doi:10.11 77/104346300012002004

5) Chen, Y., Yang, S., \& Zhao, Y. (2008). A Simultaneous Model of Consumer Brand Choice and Negotiated Price.Management Science, 54(3), 538-549. doi:10.1287/mnsc. 1070.0815

6) Duvan, B.S., \& Ozturkcan, S. (2009). Used Car Remarketing. In: International Conference on Social Sciences (ICSS), Izmir, Turkey.

7) Esteban, S., \& Shum, M. (2007). Durable- goods oligopoly with secondary markets: The case of automobiles. The RAND Journal of Economics, 38(2), 332-354. doi:10.1111/ j.1756-2171.2007.tb00071.x

8) Haan, M.A., \& de Boer, H. (2010). Has the Internet Eliminated Regional Price Differences?, Evidence from the Used Car Market. De Economist, 158(4), 373-386. doi:10.1007/ s10645-010-9151-4

9) Kapferer, J.N. (2008). The new strategic brand management: Creating and sustaining brand equity long term. Kogan Page.

10) Morton, F.S., Zettelmeyer, F., \& Silva-Risso, J. (2004). A test of bargaining theory in the auto retailing industry. Working Paper, Yale University.

11) Odekerken-Schröder, G., Hennig-Thurau, T., \& Knaevelsrudd, A.B. (2010). Exploring the Post-Termination Stage of Consumer-Brand Relationships: An Empirical Investigation of the Premium Car Market. Journal of Retailing, 86, 372-385. doi:10.1016/j.jretai.2010.09.004

12) Odekerken-Schröder, G., Ouwersloot, H., Lemmink, J., \& Janjaap, S. (2003). Consumers' trade-off between relationship, service package and price: An empirical study in the car industry. European Journal of Marketing,37(1), 219-242. doi:10.1108/03090560310454262

13) Schiraldi, P. (2011). Automobile Replacement: A Dynamic Structural Approach. The RAND Journal of Economics,42(2), 266-291. 10.1111/j.1756-2171.2011.00133.x.

14) Verhoef, P.C., Langerak, F., \& Donkers, B. (2007). Understanding Brand and Dealer Retention in the New Car Market. The Moderating Role of Brand Type Journal of Retailing, 83(1), 97-113. doi:10.1016/ j.jretai.2006.10.007

15) Vigripat, T., \& Peng, C. (2007). An Empirical Investigation of the Relationship Between Service Quality, Brand Image, Trust, Customer Satisfaction, Repurchase Intention, and Recomendation to Others. Bangkok: Asia Pacific Decision Sciences Institute.

16) Yee, C.J., San, N.C., \& Khoon, C.H. (2011). Consumers' Perceived Quality, Perceived Value and Perceived Risk Towards Purchase Decision on Automobile. American Journal of Economics and Business Administration, 3(1), 47-57.

Paper sent to revision: 29.07.2016.

Paper ready for publication: 16.12.2016. 